\title{
Area deprivation predicts lung function independently of education and social class
}

\author{
S. Shohaimi*, A. Welch*, S. Bingham*, R. Luben*, N. Day*, N. Wareham*, K-T. Khaw*
}

Area deprivation predicts lung function independently of education and social class. S. Shohaimi, A. Welch, S. Bingham, R. Luben, N. Day, N. Wareham, K-T. Khaw. (C) ERS Journals Ltd 2004.

ABSTRACT: The cross-sectional association between socioeconomic status (at both the individual and area-based level) and lung function, as measured by forced expiratory volume in one second, in a large population-based cohort was investigated.

The study population consisted of 22,675 males and females aged 39-79 yrs. They were recruited from the general community in Norfolk, UK using general practice age/sex registers, as part of the European Prospective Investigation into Cancer (EPIC-Norfolk).

It was found that being in a manual occupational social class, having no educational qualifications and living in a deprived area all independently predicted significantly lower lung function, even after controlling for smoking habit.

The influence of area-deprivation on lung function, independent of individual socioeconomic status and of individual smoking habit, suggests that apart from targeting individuals who are at high-risk, such as smokers, environmental determinants also need to be examined when considering measures to improve respiratory health. Eur Respir J 2004; 24: 157-161.
*Institute of Public Health, University of Cambridge, and ${ }^{\#}$ MRC Dunn Nutrition Unit, Cambridge, UK.

Correspondence: K-T. Khaw, Clinical Gerontology Unit, University of Cambridge, Addenbrookes Hospital, Box 2E, Cambridge CB2 2QQ.

Fax: 441223336928

E-mail:kk101@medschl.cam.ac.uk

Keywords: Education

forced expiratory volume in one second

lung function

residential deprivation

social class

Received: July 302003

Accepted after revision: February 162004
Socioeconomic differentials in health are well-established. Individuals of lower socioeconomic status have a higher risk of mortality and morbidity compared to those of higher socioeconomic status [1]. Much of the research, however, has concentrated on mortality and morbidity from cardiovascular diseases [2, 3] and cancer [4, 5]. Less is known about the association between socioeconomic status and respiratory diseases and lung function. Recent studies have shown that poor lung function measured by forced expiratory volume in one second (FEV1) is a strong predictor of mortality from cardiovascular diseases, stroke and lung cancer [6-8] independent of smoking. The nature of the relationship between FEV1 and mortality is not well understood. It is possible that both may be a result of common factors, such as cigarette smoking, physical inactivity [9] and obesity [10, 11] which could be linked to socioeconomic status.

Several studies have investigated the association between socioeconomic status and respiratory diseases. PRESCOTT et al. [12], for example, reported that socioeconomic status affects the risk of developing chronic obstructive pulmonary diseases, while HoLE et al. [6] found that those with higher relative FEV1 were less likely to be in social class IV or V. Another study found that manual workers had significantly worse lung function compared to nonmanual workers [13]. Most of these studies, however, mainly used individual-based measures of socioeconomic status. It has been suggested that in order to encompass the full extent of socioeconomic influences, the use of both individual and area-based measures of socioeconomic status is required [3]. This study reports the cross-sectional investigation into the association between respiratory function as measured by FEV1 and socioeconomic status at both the individual and area-based level, in a large population-based cohort.

\begin{abstract}
Methods
The study population comprises males and females aged 39-79 yrs who were identified from collaborating general practice age/sex registers around Norfolk. The cohort was recruited between 1993-1997 as part of the Norfolk component of the European Prospective Investigation into Cancer (EPIC-Norfolk) which was designed to investigate the aetiology of major chronic diseases. A total of 77,630 males and females were identified and invited by mail to participate in the baseline survey; $30,445(45 \%)$ agreed to participate, gave informed consent and completed a detailed health and lifestyle questionnaire. Of these, 25,639 agreed to attend a health check, but 1,675 were excluded because their addresses could not be postcoded and thus could not be assigned a Townsend deprivation score. A total of 449 participants gave insufficient information regarding their occupation and 79 had their social class coded as unclassified, while a further two individuals did not indicate their educational level. These individuals were excluded from analysis. Those with their FEV1 measurements, height, weight and smoking status missing ( $\mathrm{n}=552 ; 24 ; 12$; and 172 respectively) were also excluded. The present analyses are therefore based on 10,370 males and 12,305 females with complete data on all variables used in the analyses.

Detailed descriptions of the recruitment and study methodology have been previously reported [14]. Information on occupation, educational level, smoking status and respiratory illnesses were obtained from the health and lifestyle questionnaire. Social class was classified according to the Registrar General's occupation-based classification scheme. For males, social class was coded using their current occupation at the time of survey except when they were unemployed, in which
\end{abstract}


case their partner's social class was used; while last employment was used for males who were retired. Unemployed males without partners were unclassified. Social class in females was based on their partner's except when the partner's social class was unclassified, missing or if they had no partner; in which case social class was based on their own occupation. An unemployed female without a partner was coded as unclassified.

Educational status was based on the highest qualification attained and was categorised into four groups: degree or equivalent, A-level or equivalent, $\mathrm{O}$-level or equivalent and less than O-level or no qualifications. O-level indicates educational attainment to the equivalent of completion of schooling to the age of 15 yrs and A-level indicates educational attainment to the equivalent of completion of schooling to the age of $17 \mathrm{yrs}$.

The Townsend Deprivation Index was used to measure residential area deprivation rather than any other index, as the score does not include occupational social class data. Participants were attributed to a 1991 census enumeration district based on their postcodes at time of survey. Using variables derived from the census, the Townsend score was generated for each district as a measure of material deprivation [15]. The participants were then grouped into quintiles of Townsend deprivation index by their score.

Following completion of the health and lifestyle questionnaire, participants' height and weight were measured with participants wearing light clothing and with their shoes removed. Height was measured to the nearest $0.1 \mathrm{~cm}$ using a stadiometer, whilst weight was measured to the nearest $100 \mathrm{~g}$ using Salter scales. FEV1 was measured at initial recruitment using an electronic turbine spirometer (Micro Medical Ltd, Rochester, UK) with the higher of two consecutive expirations recorded after a practice blow. The FEV1 is treated as a continuous variable. Cigarette smoking status was derived from the questions: "Have you ever smoked as much as one cigarette a day for as long as a year?" and "Do you smoke cigarettes now?" Participants were then categorised as "current smoker" if they were regular cigarette smokers at the time of study; never smokers if they answered "no" to the question: "Have you ever smoked as much as one cigarette a day for as long as a year?" Participants were defined as diagnosed with respiratory illnesses if they answered in the affirmative to the question: "Has a doctor ever told you that you have asthma/bronchitis/emphysema?"

The analyses were undertaken separately for males and females and were also stratified by smoking status: either "ever smokers" (individuals who were current or former smokers) and "never smokers". FEV1 measures were tabulated according to the three measures of socioeconomic status: social class, level of education and deprivation level (based on Townsend deprivation index). The ANOVA and generalised linear models test for linearity was used with the $\mathrm{p}$-value of $<0.05$ for statistical significance.

The independent effect of the area-based measure of socioeconomic status on lung function was investigated. Regression models were constructed to compare the relative strength of association between the three socioeconomic status indicators and FEV1. Social class, educational level and areabased deprivation were categorised as dichotomous variables. Social classes I, II and III nonmanual were classified as "nonmanual", while social classes III manual, IV and V were classified as "manual". Educational level was categorised into "at least O-level" (which includes O-level, A-level and degree) and "no qualifications". For residential deprivation, subjects with Townsend scores of $<0$ were classified as "less deprived", whilst those with Townsend scores of $>0$ were categorised as "most deprived". The use of 0 as the cut-off point for the Townsend deprivation level allows for comparisons with those who are below the national average, in terms of deprivation based on the Townsend deprivation scores. The study further investigated the effects of deprivation level on FEV1 in a population stratified by ever smokers and never smokers. Age, height and weight were included as a covariate in all of the models.

\section{Results}

Characteristics of the study population at baseline survey are shown in table 1. Males were slightly older, taller, weighed more and had a higher FEV1 compared to females. The proportion of current smokers was similar in males and females, however, more than half of the females were never smokers compared to only a third of males. In both males and females, never smokers had higher FEV1 compared to those who were current or former smokers (ever smokers) (table 2). There was a clear socioeconomic gradient in lung function measured by FEV1. Lung function decreased with decreasing levels of socioeconomic status measured by either social class, educational level or quintiles of Townsend deprivation index. This social gradient was observed in both ever smokers and never smokers. The difference in FEV1 between different levels of socioeconomic status was more pronounced in ever smokers compared to never smokers. For example, in males who were ever smokers, the difference between FEV1 in individuals with a degree and those with no qualifications was $460 \mathrm{~mL}$, compared to $360 \mathrm{~mL}$ in never smokers. Adjusting for height and weight somewhat attenuated the association between socioeconomic status and FEV1, but the association remained highly significant except for social class in males who were never smokers.

Social class, educational level and residential area-deprivation independently predicted lung function as measured by FEV1 (table 3) in the multivariate regression analysis, which also adjusted for potential confounders (age, height, weight, smoking status and respiratory illnesses). Individuals who were in manual social classes with no educational qualifications, or those who lived in the most deprived areas, had poorer lung function compared to those in nonmanual social classes, with at least O-level or equivalent educational attainment, or who lived in less deprived areas. Educational level was strongest predictor of lung function in both males and females. In males, the magnitude of effect of residential areadeprivation was stronger than occupational social class, and was as strong as educational level, whilst in females, the influence of residential area-deprivation on lung function was as strong as social class. Adjusting for height greatly reduced the association between social class and FEV1, and to some extent the association between educational level and FEV1. However, the effect of area-deprivation on lung function was

Table 1.-Baseline characteristics of 10,370 males and 12,305 females aged 39-79 yrs of the European Prospective Investigation into Cancer, Norfolk (EPIC-Norfolk) cohort, 1993-1997

\begin{tabular}{lcc}
\hline & Males & Females \\
\hline Age yrs & $59.0 \pm 9.3$ & $58.2 \pm 9.3$ \\
Height cm & $174.0 \pm 6.6$ & $161.0 \pm 6.2$ \\
Weight kg & $80.4 \pm 11.5$ & $68.0 \pm 11.9$ \\
FEV1 L & $2.90 \pm 0.7$ & $2.14 \pm 0.5$ \\
Current smokers & $1267(12.2)$ & $1399(11.4)$ \\
Former smokers & $5637(54.4)$ & $3944(32.1)$ \\
Never smokers & $3466(33.4)$ & $6962(56.6)$ \\
\hline
\end{tabular}

Data are presented as mean \pm SD or $\mathrm{n}(\%)$. FEV1: forced expiratory volume in one second. 
Table 2. - Distribution of mean forced expiratory volume in one second (FEV 1 ) at baseline survey by social class, educational level and deprivation category for 10,370 males and 12,305 females aged 39-79 yrs, European Prospective Investigation into Cancer, Norfolk (EPIC-Norfolk) cohort, 1993-1997"

\begin{tabular}{|c|c|c|c|c|c|c|c|c|}
\hline & \multicolumn{4}{|c|}{ Males } & \multicolumn{4}{|c|}{ Females } \\
\hline & \multicolumn{2}{|c|}{ Ever smokers $(n=6904)$} & \multicolumn{2}{|c|}{ Never smokers $(n=3466)$} & \multicolumn{2}{|c|}{ Ever smokers $(\mathrm{n}=5343)$} & \multicolumn{2}{|c|}{ Never smokers $(n=6962)$} \\
\hline & Subjects $\mathrm{n}$ & FEV1 L & Subjects $\mathrm{n}$ & FEV1 L & Subjects $\mathrm{n}$ & FEV1 L & Subjects $\mathrm{n}$ & FEV1 L \\
\hline \multicolumn{9}{|l|}{ Social class } \\
\hline I & 403 & $2.92(0.03)$ & 380 & $3.09(0.03)$ & 292 & $2.16(0.02)$ & 494 & $2.22(0.02)$ \\
\hline II & 2481 & $2.83(0.01)$ & 1474 & $3.09(0.01)$ & 1831 & $2.14(0.01)$ & 2454 & $2.20(0.01)$ \\
\hline III nonmanual & 894 & $2.79(0.02)$ & 413 & $3.13(0.03)$ & 1083 & $2.10(0.01)$ & 1377 & $2.17(0.01)$ \\
\hline III manual & 1901 & $2.77(0.01)$ & 737 & $3.12(0.02)$ & 1172 & $2.08(0.01)$ & 1460 & $2.13(0.01)$ \\
\hline IV & 991 & $2.75(0.02)$ & 379 & $3.05(0.03)$ & 750 & $2.04(0.02)$ & 894 & $2.12(0.01)$ \\
\hline $\mathrm{V}$ & 234 & $2.62(0.04)$ & 83 & $3.09(0.06)$ & 215 & $2.00(0.03)$ & 283 & $2.12(0.02)$ \\
\hline $\mathrm{p}$-value for trend & \multicolumn{2}{|c|}{$<0.001$} & \multicolumn{2}{|c|}{0.35} & \multicolumn{2}{|c|}{$<0.001$} & \multicolumn{2}{|c|}{$<0.001$} \\
\hline \multicolumn{9}{|l|}{ Educational level } \\
\hline Degree or equivalent & 797 & $2.88(0.02)$ & 800 & $3.13(0.02)$ & 522 & $2.20(0.02)$ & 813 & $2.22(0.01)$ \\
\hline A-level or equivalent & 3167 & $2.82(0.01)$ & 1570 & $3.11(0.01)$ & 1407 & $2.13(0.01)$ & 1775 & $2.20(0.01)$ \\
\hline O-level or equivalent & 618 & $2.78(0.02)$ & 302 & $3.06(0.03)$ & 811 & $2.10(0.01)$ & 1210 & $2.18(0.01)$ \\
\hline No qualifications & 2322 & $2.74(0.01)$ & 794 & $3.05(0.02)$ & 2603 & $2.06(0.01)$ & 3164 & $2.13(0.01)$ \\
\hline p-value for trend & \multicolumn{2}{|c|}{$<0.001$} & \multicolumn{2}{|c|}{0.02} & \multicolumn{2}{|c|}{$<0.001$} & \multicolumn{2}{|c|}{$<0.001$} \\
\hline \multicolumn{9}{|l|}{ Deprivation category } \\
\hline $1(<-3.80)$ & 1313 & $2.87(0.02)$ & 831 & $3.13(0.02)$ & 1008 & $2.14(0.01)$ & 1508 & $2.19(0.01)$ \\
\hline $2(-3.79$ to -2.92$)$ & 1439 & $2.82(0.02)$ & 781 & $3.12(0.02)$ & 1083 & $2.11(0.01)$ & 1473 & $2.18(0.01)$ \\
\hline $3(-2.91$ to -2.09$)$ & 1290 & $2.82(0.02)$ & 683 & $3.09(0.02)$ & 982 & $2.10(0.01)$ & 1360 & $2.18(0.01)$ \\
\hline $4(-2.08$ to -0.55$)$ & 1429 & $2.73(0.02)$ & 646 & $3.08(0.02)$ & 1105 & $2.11(0.01)$ & 1392 & $2.14(0.01)$ \\
\hline $5(>-0.54)$ & 1433 & $2.73(0.02)$ & 525 & $3.04(0.02)$ & 1165 & $2.05(0.01)$ & 1229 & $2.14(0.01)$ \\
\hline $\mathrm{p}$-value for trend & \multicolumn{2}{|c|}{$<0.001$} & \multicolumn{2}{|c|}{0.03} & \multicolumn{2}{|c|}{$<0.001$} & \multicolumn{2}{|c|}{$<0.001$} \\
\hline
\end{tabular}

Data are presented as mean (SE) unless otherwise stated. ${ }^{\#}$ : stratified by smoking status and adjusted for age, height and weight; ${ }^{\curvearrowleft}$ : based on Townsend deprivation scores.

only slightly reduced after adjusting for height. The independent effects of social class, educational level and areadeprivation on lung function were still evident in both males and females after stratifying by smoking status (ever and never smokers), with the exception of social class in males who were never smokers (table 4). The findings were consistent when analyses were stratified by age group (below and above 60 yrs) (results not shown).

\section{Discussion}

In this cross-sectional investigation of the association between socioeconomic status and lung function, strong independent effects of occupational social class, educational level and residential area-deprivation on FEV1 were found. This association was observed even after controlling for smoking and other known confounders; age, height, weight and respiratory illnesses. It was found that males and females of lower socioeconomic status had poorer lung function compared to those of higher socioeconomic status. This is consistent with findings from previous studies investigating the influence of socioeconomic status on lung function.

It is unlikely that the independent effects observed for residential area-deprivation could be explained by confounding. By adjusting for known predictors of FEV1 and stratifying by smoking status, the possible confounding effect

Table 3.-Regression coefficients (SE) for mean forced expiratory volume in one second in 10,370 males and 12,305 females aged 39-79 yrs, of the European Prospective Investigation into Cancer, Norfolk (EPIC-Norfolk) cohort, 1993-1997 for models based on social class, level of education and deprivation level

\begin{tabular}{|c|c|c|c|c|c|c|c|c|c|c|}
\hline \multirow[t]{2}{*}{ Predictor variables } & \multicolumn{2}{|c|}{ Model 1} & \multicolumn{2}{|c|}{ Model 2} & \multicolumn{2}{|c|}{ Model 3} & \multicolumn{2}{|c|}{ Model 4} & \multicolumn{2}{|c|}{ Model 5} \\
\hline & $\beta(\mathrm{SE})$ & p-value & $\beta(\mathrm{SE})$ & p-value & $\beta(\mathrm{SE})$ & p-value & $\beta(\mathrm{SE})$ & $\mathrm{p}$-value & $\beta(\mathrm{SE})$ & p-value \\
\hline \multicolumn{11}{|l|}{ Males } \\
\hline Social class ${ }^{\#}$ & $-0.1(0.01)$ & $<0.001$ & $-0.09(0.019)$ & $<0.001$ & $-0.08(0.01)$ & $<0.001$ & $-0.03(0.01)$ & 0.04 & $-0.03(0.01)$ & 0.004 \\
\hline Education & $-0.1(0.01)$ & $<0.001$ & $-0.09(0.01)$ & $<0.001$ & $-0.09(0.01)$ & $<0.001$ & $-0.07(0.01)$ & $<0.001$ & $-0.07(0.01)$ & $<0.001$ \\
\hline Deprivation level $^{+}$ & $-0.08(0.02)$ & $<0.001$ & $-0.07(0.02)$ & $<0.001$ & $-0.07(0.02)$ & $<0.001$ & $-0.06(0.02)$ & $<0.001$ & $-0.06(0.02)$ & $<0.001$ \\
\hline \multicolumn{11}{|l|}{ Females } \\
\hline Social class $\#$ & $-0.07(0.008)$ & $<0.001$ & $-0.07(0.008)$ & $<0.001$ & $-0.08(0.008)$ & $<0.001$ & $-0.05(0.008)$ & $<0.001$ & $-0.050 .008)$ & $<0.001$ \\
\hline Education & $-0.09(0.008)$ & $<0.001$ & $-0.08(0.008)$ & $<0.001$ & $-0.08(0.0082)$ & $<0.001$ & $-0.05(0.008)$ & $<0.001$ & $-0.06(0.008)$ & $<0.001$ \\
\hline Deprivation level $^{+}$ & $-0.05(0.01)$ & $<0.001$ & $-0.04(0.01)$ & $<0.001$ & $-0.05(0.01)$ & $<0.001$ & $-0.05(0.018)$ & $<0.001$ & $-0.04(0.01)$ & $<0.001$ \\
\hline
\end{tabular}

Model 1: age; model 2: age and smoking status; model 3: age, smoking status and weight; model 4: age, smoking status, weight and height; model 5: age, smoking status, weight, height and respiratory illness. Regression coefficients are shown as the difference in litres from the reference category, adjusted for the other factors in the model. Predictor variables: social class (nonmanual: social classes I, II and III nonmanual; manual: social classes III manual, IV and V); education (at least O-level, no qualifications); deprivation level (based on Townsend deprivation scores: $<0=1$ less deprived, $>0=$ highly deprived). ${ }^{\#}$ : manual versus nonmanual; ${ }^{\uparrow}$ : no qualifications versus at least O-level; ${ }^{+}$: highly deprived versus less deprived. 
Table 4.-Regression coefficients $(95 \% \mathrm{Cl})$ for mean forced expiratory volume in one second in 10,370 males and 12,305 females aged 39-79 yrs, of the European Prospective Investigation into Cancer-Norfolk (EPIC-Norfolk) cohort, 1993-1997

\begin{tabular}{|c|c|c|c|c|}
\hline \multirow[t]{2}{*}{ Predictor variables } & \multicolumn{2}{|l|}{ Males } & \multicolumn{2}{|l|}{ Females } \\
\hline & Regression coefficients $\beta(95 \% \mathrm{CI})$ & p-value & Regression coefficients $\beta(95 \% \mathrm{CI})$ & p-value \\
\hline \multicolumn{5}{|l|}{ Ever smokers } \\
\hline Social class ${ }^{\#}$ & $-0.048(-0.08--0.01)$ & 0.02 & $-0.047(-0.07--0.02)$ & $<0.001$ \\
\hline Education & $-0.065(-0.10--0.03)$ & $<0.001$ & $-0.053(-0.08--0.02)$ & $<0.001$ \\
\hline Deprivation level $^{+}$ & $-0.067(-0.10--0.03)$ & $<0.001$ & $-0.064(-0.09--0.04)$ & $<0.001$ \\
\hline \multicolumn{5}{|l|}{ Never smokers } \\
\hline Social class $\#$ & $0.019(-0.02-0.06)$ & 0.37 & $-0.049(-0.07--0.02)$ & $<0.001$ \\
\hline Education & $-0.06(-0.11--0.01)$ & 0.01 & $-0.052(-0.07--0.03)$ & $<0.001$ \\
\hline Deprivation level $^{+}$ & $-0.059(-0.12--0.002)$ & 0.04 & $-0.029(-0.06--0.003)$ & 0.03 \\
\hline
\end{tabular}

Regression coefficients are shown as the difference in litres from the reference category, adjusted for the other factors in the model. Predictor variables: social class (nonmanual: social classes I, II and III nonmanual; manual: social classes III manual, IV and V); education (at least O-level, no qualifications); deprivation level (based on Townsend deprivation scores: $<0=$ less deprived, $>0=$ highly deprived). "\#: manual versus nonmanual; ": no qualifications versus at least O-level; highly deprived versus less deprived; $\$$ : for models based on social class, level of education and deprivation level stratified by smoking status and adjusted for age, height and weight.

of smoking, which is strongly associated with reduced lung function, was minimised. While it is possible that there may be some under-reporting of respiratory illnesses by individuals of lower socioeconomic status, this would only result in underestimation of the influences of socioeconomic status on FEV1.

With a response rate of about $45 \%$, this study population was not a random population sample. However, characteristics of the study population were similar to those from the Health Survey for England population samples [14]. The exclusion of individuals whose social class and deprivation scores were missing or not classified could cause bias only if they differed from those included in the study (with respect to the relationship between social class and lung function or area-based deprivation and lung function). The cohort seems to have favourable Townsend deprivation scores compared to the national average. This could be attributed to the indices used in the score, such as car ownership and overcrowded housing, which may be more appropriate for urban environments and may not be sensitive to rural deprivation, such as that which occurs in Norfolk. Nevertheless, there is still a wide range of deprivation level, social class and educational level in this population to show a clear socioeconomic gradient in lung function.

There are several ways by which area-deprivation could influence lung function. Poor housing conditions, use of gas stoves and household overcrowding, which are characteristics of areas of high material deprivation, are more likely to increase risks of respiratory infections [16]. Although the effect of smoking has been accounted for, highly-deprived areas have been shown to have higher proportions of current smokers [17], and thus individuals in these areas are more likely to be exposed to environmental tobacco smoke, which is associated with an elevated risk of respiratory symptoms [18]. It has also been shown that areas of high deprivation have poorer air quality [19]. There was no available information on duration of residence; so whether the association between area-deprivation and lung function reflects current or past exposures is unknown. However, the population in Norfolk is relatively stable compared to elsewhere in the UK.

Another explanation for poor lung function in adult life is that it may be a consequence of low lung function at birth or decreased lung function during childhood and adolescence [20]. This may be closely related to an individual's childhood socioeconomic circumstances and involves diet, exposure to infection and stress due to adverse socioeconomic conditions $[21,22]$. Both education and occupational social class are likely to reflect life-course socioeconomic experience, whilst area-deprivation is more likely to be related to exposures during adulthood. In a separate analysis, height, which is a marker of exposures influencing growth throughout childhood [23], was found to be significantly associated with social class by occupation and educational level, but not areadeprivation (data not shown).

Other factors apart from smoking, pollution and early life exposures have been reported to influence adult lung function. These include diet and physical activity. Recent studies report that antioxidants reduce the rate of loss of lung function [24, 25] and physical inactivity, such as high daily televisionviewing hours, are associated with lower lung function [9].

The strong effect of education in both males and females could be explained by differences in diet and lifestyle factors. Education may enable individuals to make more informed choices of food and particular lifestyles. For example, the intake of fruit, vegetables and wine, all rich antioxidants, are significantly higher in individuals of high socioeconomic status. High antioxidant or fruit and vegetable intake have been suggested to be beneficial for respiratory function.

The observed association between socioeconomic status and forced expiratory volume in one second was modest (difference ranging from 26-65 $\mathrm{mL}$ ), compared to the average rate of decline of $15 \mathrm{~mL} \cdot \mathrm{yr}^{-1}$ in lung function in moderate to heavy male smokers [26]. However, given the strong inverse relationship between forced expiratory volume in one second and mortality, a small difference in lung function is associated with demonstrable differences in mortality risk, independent of smoking habit. Whether this relationship is causal, is yet to be demonstrated, but it may be possible to influence lung function, and possibly future mortality risk. Individuals who quit smoking, for example, have been shown to have a rate of decline in forced expiratory volume in one second similar to that of never smokers [27]. In any case, good lung function is associated with subjective well-being. Cigarette smoking is undoubtedly the single most important determinant of lung function. The specific components of area deprivation that influence lung function, independent of personal smoking habits, are still unclear, but are likely to include air quality and housing. However, the influence of area-deprivation on lung function, independent of individual socioeconomic status and of individual smoking habit, suggests that apart from targeting individuals who are at high-risk, such as smokers, environmental determinants also need to be examined when considering measures to improve respiratory health. 
Acknowledgements. The authors thank the participants and general practitioners who took part in the study and the staff of EPIC-Norfolk. EPICNorfolk is supported by research programme grant funding from the Cancer Research Campaign and Medical Research Council with additional support from the Stroke Association, British Heart Foundation, Department of Health, Europe Against Cancer Programme Commission of the European Union, Food Standards Agency and Wellcome Trust.

\section{References}

1. Acheson D. Independent Inquiry into Inequalities in Health Report. London, Stationery Office, 1999.

2. Blane D, Hart CL, Smith GD, Gillis CR, Hole DJ, Hawthorne VM. Association of cardiovascular disease risk factors with socioeconomic position during childhood and during adulthood. BMJ 1996; 313: 1434-1438.

3. Smith GD, Hart C, Watt G, Hole D, Hawthorne V. Individual social class, area-based deprivation, cardiovascular disease risk factors, and mortality: the Renfrew and Paisley Study. J Epidemiol Community Health 1998; 52: 399-405.

4. Martikainen P, Lahelma E, Ripatti S, Albanes D, Virtamo J. Educational differences in lung cancer mortality in male smokers. Int J Epidemiol 2001; 30: 264-267.

5. Tavani A, Fioretti F, Franceschi S, et al. Education, socioeconomic status and risk of cancer of the colon and rectum. Int J Epidemiol 1999; 28: 380-385.

6. Hole DJ, Watt GC, Davey-Smith G, Hart CL, Gillis CR, Hawthorne VM. Impaired lung function and mortality risk in men and women: findings from the Renfrew and Paisley prospective population study. BMJ 1996; 313: 711-716.

7. Schunemann HJ, Dorn J, Grant BJ, Winkelstein W Jr, Trevisan M. Pulmonary function is a long-term predictor of mortality in the general population: 29-year follow-up of the Buffalo Health Study. Chest 2000; 118: 656-664.

8. Truelsen T, Prescott E, Lange P, Schnohr P, Boysen G. Lung function and risk of fatal and non-fatal stroke. The Copenhagen City Heart Study. Int J Epidemiol 2001; 30: $145-151$.

9. Jakes RW, Day NE, Patel B, et al. Physical inactivity is associated with lower forced expiratory volume in 1 second: European Prospective Investigation into Cancer-Norfolk Prospective Population Study. Am J Epidemiol 2002; 156: 139-147.

10. Santana H, Zoico E, Turcato E, et al. Relation between body composition, fat distribution, and lung function in elderly men. Am J Clin Nutr 2001; 73: 827-831.

11. Collins LC, Hoberty PD, Walker JF, Fletcher EC, Peiris AN. The effect of body fat distribution on pulmonary function tests. Chest 1995; 107: 1298-1302.

12. Prescott E, Lange P, Vestbo J. Socioeconomic status, lung function and admission to hospital for COPD: results from the Copenhagen City Heart Study. Eur Respir J 1999; 13: $1109-1114$.

13. Hart CL, Hole DJ, Gillis CR, Smith GD, Watt GC, Hawthorne VM. Social class differences in lung cancer mortality: risk factor explanations using two Scottish cohort studies. Int J Epidemiol 2001; 30: 268-274.

14. Day N, Oakes S, Luben R, et al. EPIC-Norfolk: Study design and characteristics of the cohort. Br J Cancer 1999; 80: 95-103.

15. Townsend $\mathrm{P}$, Phillimore $\mathrm{P}$, Beattie A. Health and deprivation: inequality and the North. London, Croom Helm, 1988.

16. Prescott E, Vestbo J. Socioeconomic status and chronic obstructive pulmonary disease. Thorax 1999; 54: 737-741.

17. Shohaimi S, Luben R, Wareham N, et al. Residential area deprivation predicts smoking habit independently of individual educational level and occupational social class. A cross sectional study in the Norfolk cohort of the European Investigation into Cancer (EPIC-Norfolk). $J$ Epidemiol Community Health 2003; 57: 270-276.

18. Leuenberger P, Schwartz J, Ackermann-Liebrich U, et al. Passive smoking exposure in adults and chronic respiratory symptoms (SAPALDIA Study). Swiss Study on Air Pollution and Lung Diseases in Adults, SAPALDIA Team. Am J Respir Crit Care Med 1994; 150: 1222-1228.

19. Pless-Mulloli T, Phillimore P, Moffatt S, et al. Lung cancer, proximity to industry, and poverty in northeast England. Environ Health Perspect 1998; 106: 189-196.

20. Weiss ST, Ware JH. Overview of issues in the longitudinal analysis of respiratory data. Am J Respir Crit Care Med 1996; 154: S208-S211.

21. Gunnell D. Can adult anthropometry be used as a 'biomarker' for prenatal and childhood exposures? Int J Epidemiol 2002; 31: 390-394.

22. Strachan DP. Ventilatory function, height, and mortality among lifelong non-smokers. J Epidemiol Community Health 1992; 46: 66-70.

23. Gunnell D, Whitley E, Upton MN, McConnachie A, Smith GD, Watt GC. Associations of height, leg length, and lung function with cardiovascular risk factors in the Midspan Family Study. J Epidemiol Community Health 2003; 57: 141146.

24. McKeever TM, Scrivener S, Broadfield E, Jones Z, Britton J, Lewis SA. Prospective study of diet and decline in lung function in a general population. Am J Respir Crit Care Med 2002; 165: 1299-1303.

25. Schunemann HJ, McCann S, Grant BJ, Trevisan M, Muti P, Freudenheim JL. Lung function in relation to intake of carotenoids and other antioxidant vitamins in a populationbased study. Am J Epidemiol 2002; 155: 463-471.

26. Kerstjens HA, Rijcken B, Schouten JP, Postma DS. Decline of FEV1 by age and smoking status: facts, figures, and fallacies. Thorax 1997; 52: 820-827.

27. Anthonisen NR, Connett JE, Kiley JP, et al. Effects of smoking intervention and the use of an inhaled anticholinergic bronchodilator on the rate of decline of FEV1. The Lung Health Study. JAMA 1994; 272: 1497-1505. 